\title{
Polysomy 7
}

National Cancer Institute

\section{Source}

National Cancer Institute. Polysomy 7. NCI Thesaurus. Code C126119.

A numerical chromosomal abnormality characterized by the presence of more than two copies of chromosome 7 in a cell. 